ORIGINAL ARTICLE

\title{
Postgraduates' Perspective of Pediatric Dental Chair: A Questionnaire Study
}

\author{
Eddula R Reddy ${ }^{1}$, Saraswati S Raju ${ }^{2}$, Kiranmayi Merum ${ }^{3}$, Thabitha Sandipamu ${ }^{4}$, Srujana M Palicarp ${ }^{5}$, Anil Kumar ${ }^{6}$
}

\begin{abstract} with traditional adult dental chair for treatment and better management of children. children. dental chair among postgraduates is overwhelming.

\section{INTRODUCTION}

Dental chair resembles most of the dental environment, and it should be appealing to eliminate fear and anxiety in children. For pediatric dentist, the dental chair should be designed in such a way that there should be both comfort and ease while doing treatment in a child. Ergonomics of adult dental chair does not help pediatric dentist to treat child efficiently and also results in work-related musculoskeletal disorders. This study is designed to know the perspective of postgraduate students on pediatric dental chair in Southern India.
\end{abstract}

The posture and positioning of pediatric dentist will greatly depend upon the type of dental chair they chose while treating children. Pediatric dentists working on a traditional adult chair for treating children frequently lean forward for close proximity to oral cavity; as a result of this poor posture, they are more prone to suffer from musculoskeletal disorders. Proper positioning of dentist during treatment will improve not only their comfort but also their career longevity. The aim of the study was to assess the comfort and need of pediatric dental chair compared

Study design: This is a questionnaire survey for postgraduate students consisting of 14 multiple-choice questions in English format. The questionnaire was structured to know whether the pediatric dental chair is beneficial compared to traditional adult dental chair while treating

Results and conclusion: Out of 92 responded members, $99 \%$ had an opinion that a pediatric dental chair is needed for treating children. They concluded that pediatric dental chair had many advantages over traditional adult dental chair while treating children and acceptance of pediatric

Keywords: Musculoskeletal problems, Pediatric dental chair, Traditional adult dental chair. International Journal of Clinical Pediatric Dentistry (2020): 10.5005/jp-journals-10005-1758

\section{Materials and Methods}

\section{Aim of the Study}

To assess the comfort and need of pediatric dental chair compared with traditional adult dental chair for treatment and better management of children among postgraduate students of Southern India.

\section{Inclusion Criteria}

Postgraduates who had an experience of working with both pediatric dental chair and adult chair for at least one year were included in the study.

A total of 100 postgraduates from 12 different institutions in southern part of India were taken in this study. After seeking permission from concerned authorities, the objectives of the study were explained to postgraduates, questionnaires were distributed, and the postgraduates were asked to mark the appropriate answer.

A questionnaire survey was designed inclusive of multiplechoice questions formulated in English. The questionnaire contained about 14 questions and was structured to know whether a pediatric dental chair is beneficial compared to traditional adult dental chair while treating children. Filled questionnaires were
${ }^{1-6}$ Department of Pedodontics and Preventive Dentistry, Kamineni Institute of Dental Sciences, Nalgonda, Telangana, India

Corresponding Author: Saraswati S Raju, Department of Pedodontics and Preventive Dentistry, Kamineni Institute of Dental Sciences, Nalgonda, Telangana, India, Phone: +91 9030912230, e-mail: srikanth1090@gmail.com

How to cite this article: Reddy ER, Raju SS, Merum K, et al. Postgraduates' Perspective of Pediatric Dental Chair: A Questionnaire Study. Int J Clin Pediatr Dent 2020;13(3):251-254.

Source of support: Nil

Conflict of interest: None

collected on the following day. The data were tabulated, and statistical analysis was done (Tables 1 and 2).

\section{Results}

Out of 100 postgraduates, 92 members had responded to the questionnaire form. Among the study population, $99 \%$ of respondents had an opinion that a pediatric dental chair is needed for treating children, out of which $40 \%$ felt comfortable using pediatric dental chair until the age of the children is 6 years, whereas

Table 1: Postgraduates' opinion regarding till what age the pediatric dental chair was comfortable

\begin{tabular}{|c|c|c|c|c|}
\hline S. no & & $\begin{array}{l}\text { Till } 6 \text { years } \\
\text { (\%) }\end{array}$ & $\begin{array}{l}6-12 \text { years } \\
\text { (\%) }\end{array}$ & $\begin{array}{l}12-18 \text { years } \\
\text { (\%) }\end{array}$ \\
\hline 1 & $\begin{array}{l}\text { According to you, } \\
\text { till what age the } \\
\text { pediatric dental } \\
\text { chair is more } \\
\text { comfortable? }\end{array}$ & 40 & 58 & 2 \\
\hline
\end{tabular}


Table 2: Postgraduates' opinion about pediatric dental chair comparing to traditional adult dental chair

\begin{tabular}{|c|c|c|c|c|}
\hline S. no & Question & Yes (\%) & No (\%) & $\begin{array}{l}\text { Cannot say } \\
(\%)\end{array}$ \\
\hline 2 & Do you have any experience of working on pediatric dental chair? & 85 & 15 & - \\
\hline 3 & Need of pediatric dental chair for treatment of children? & 99 & 1 & - \\
\hline 4 & Attractiveness of pediatric dental chair instills positive behavior attitude & 97 & 1 & 2 \\
\hline 5 & Do you feel that pediatric dental chair has leg space problem? & 36 & 44 & 20 \\
\hline 6 & Is the instrument tray size in pediatric dental chair within reach of your arms? & 69 & 18 & 13 \\
\hline 7 & Is the spittoon in a pediatric dental chair easily approachable to child? & 81 & 11 & 8 \\
\hline 8 & Is pediatric dental chair cost-effective? & 36 & 29 & 35 \\
\hline 9 & Is pediatric dental chair more comfortable for practicing four-handed dentistry? & 60 & 16 & 24 \\
\hline 10 & $\begin{array}{l}\text { Does the usage of booster seat in traditional adult dental chair substitute child } \\
\text { positioning in pediatric dental chair? }\end{array}$ & 5 & 95 & - \\
\hline 11 & Is child positioning and visibility better in pediatric dental chair? & 85 & 5 & 10 \\
\hline 12 & Is pediatric dental chair more safe to child compared to traditional adult dental chair? & 78 & 4 & 18 \\
\hline 13 & $\begin{array}{l}\text { Is pediatric dental chair more comfortable than traditional adult dental chair for } \\
\text { treating special children? }\end{array}$ & 78 & 9 & 13 \\
\hline 14 & $\begin{array}{l}\text { Is headrest adjustment and positioning of child better in a pediatric dental chair } \\
\text { compared to a traditional adult dental chair? }\end{array}$ & 82 & 9 & 9 \\
\hline
\end{tabular}

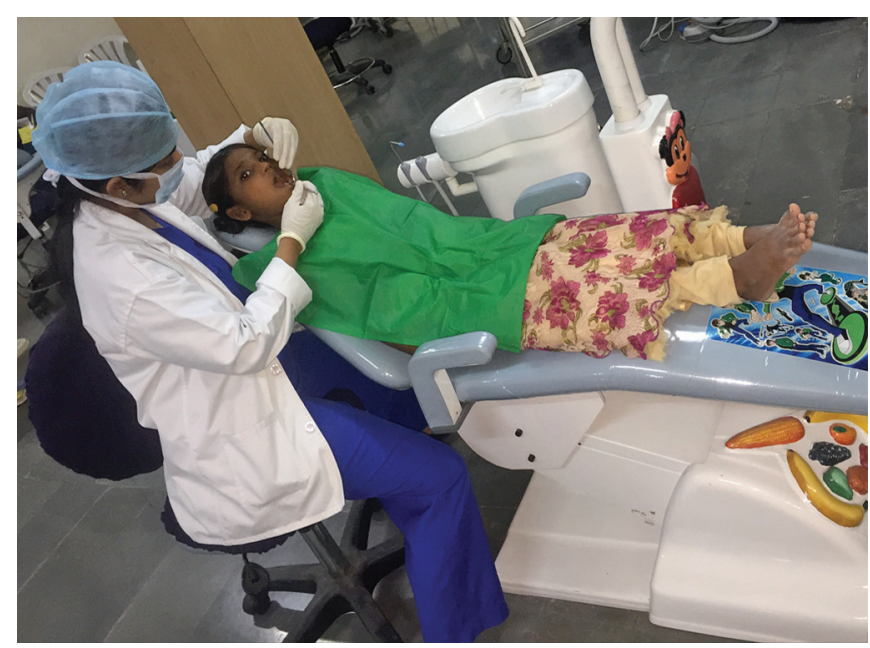

Fig. 1: Six-year-old child comfortably positioned on pediatric dental chair

$58 \%$ preferred it until 12 years and only $2 \%$ favored pediatric dental chair until 18 years.

When treating children on pediatric dental chair, $44 \%$ of study population responded that they had no leg space problem, while $36 \%$ had leg space problem and $20 \%$ did not choose any option. According to $69 \%$ of respondents, instrument tray size is within the reach of their arms in pediatric dental chair, whereas only $18 \%$ felt that instrument tray size in traditional dental chair is within the reach of their arms and 13\% are comfortable with both the dental chairs. With respect to accessibility of spittoon, $81 \%$ of them felt that it is easily approachable to child in pediatric dental chair compared to traditional adult dental chair. Only $11 \%$ preferred adult dental chair, while $8 \%$ felt that both chairs are comfortable to child for spitting (Figs 1 to 5 ).

Regarding the usage of booster seat in traditional adult dental chair that substitutes child positioning in pediatric dental chair, $70 \%$ of respondents had no experience of working with the combination of a booster seat in adult chairs. Out of $30 \%$ members, $94 \%$ members felt that a booster seat with a traditional seat cannot substitute

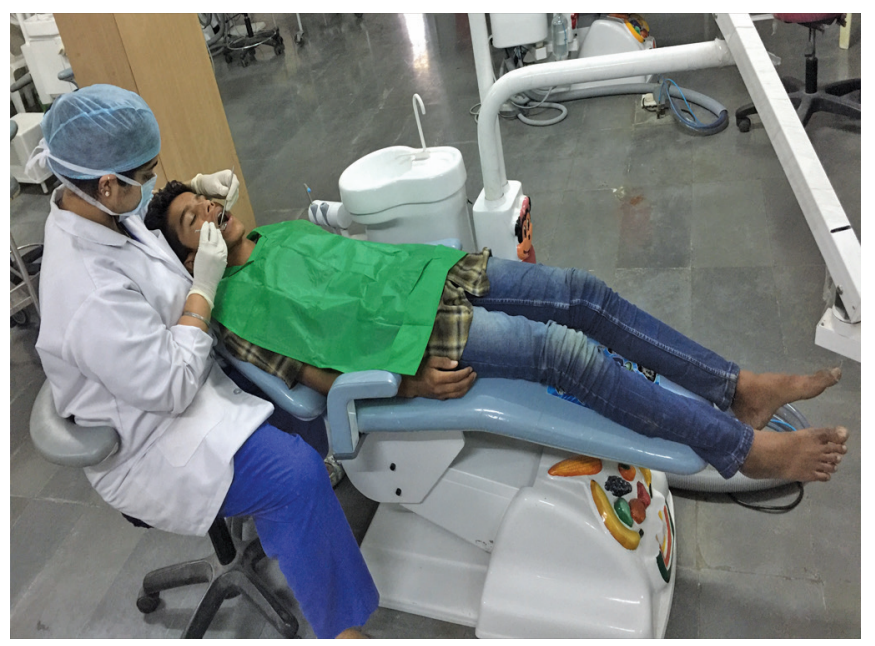

Fig. 2: Pediatric dental chair unable to accommodate child of 12 years
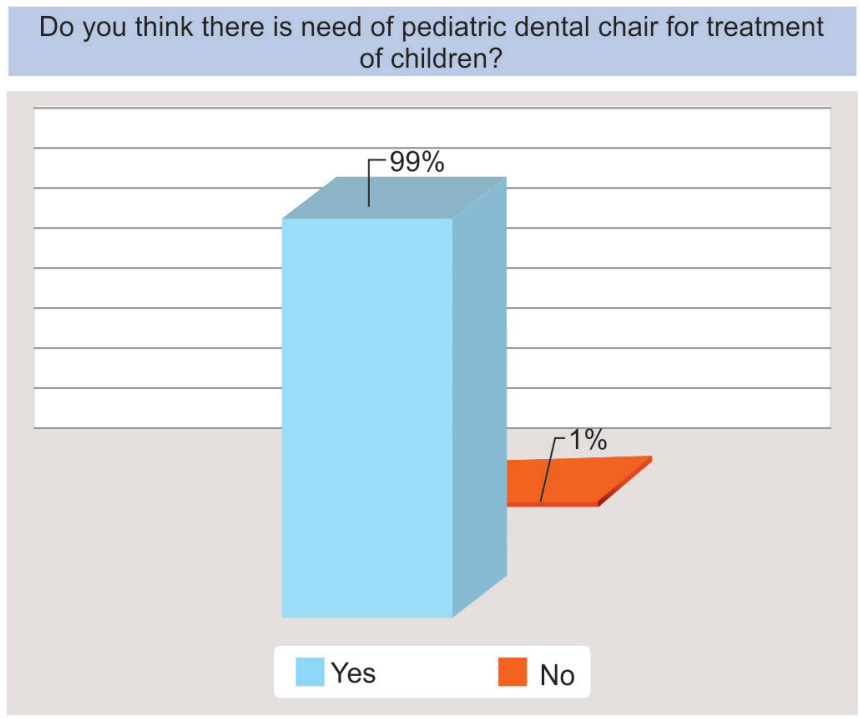

Fig. 3: Depicting the need for pediatric dental chair 


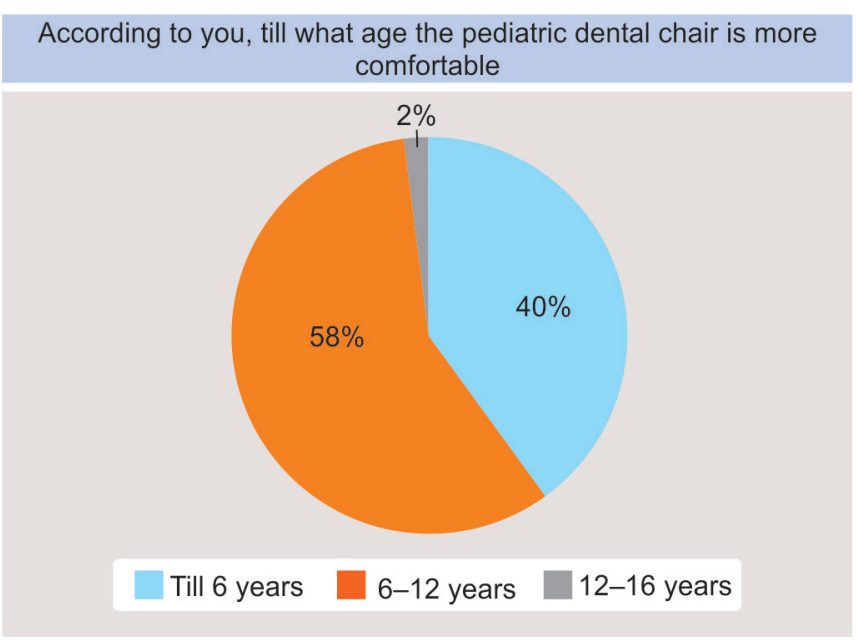

Fig. 4: Opinion regarding till what age the pediatric dental chair was comfortable

pediatric dental chair, whereas only $6 \%$ felt that this combination can substitute pediatric dental chair.

In all, 78\% of them felt that pediatric dental chair is more safe to child while managing compared to adult dental chair and headrest adjustment and positioning of child is better in pediatric dental chair (82\%) compared to adult chair, and for practicing four-handed dentistry, $60 \%$ of them supported pediatric dental chair rather than adult chair. Only $29 \%$ of them felt that it is of high cost to the benefits provided, whereas $36 \%$ of them supported its cost to the benefits provided by pediatric dental chair. However, $35 \%$ of them have not chosen any option.

Ninety-seven percent of the study population had an opinion that the attractiveness of pediatric dental chair instills a positive behavior attitude in children toward dental treatment. It was found that $78 \%$ of postgraduates preferred pediatric dental chair for treating special children than traditional adult dental chair, whereas $9 \%$ preferred adult dental chair and $13 \%$ felt that both chairs are comfortable for treating special children.

\section{Discussion}

The present study included postgraduate students from the Department of Pediatric Dentistry who have experience of working with both traditional and pediatric dental chairs. It is observed that $99 \%$ of study population supported the use of pediatric dental chair for treating young children between the age group of 6 years and 12 years. Pediatric dentist frequently leans forward for close proximity to oral cavity; as a result of this poor posture, they are more prone to suffer from musculoskeletal disorders. Mahboobeh Abdolalizadeh et al. stated that most dentists working in an asymmetric and static position for a long period cause stress in the joints, muscles, and tendons, especially in the neck, back, shoulder, and wrist body parts. ${ }^{1}$ Dentists can reduce the risk of developing musculoskeletal discomfort by using proper body posture and positioning during clinical procedures ${ }^{2}$ and there is no loss of clinical time to acquire a desired chair position while operating on pediatric dental chair. ${ }^{3}$

Fifty-eight percent of respondents were of the opinion that pediatric dental chair is comfortable till 12 years, whereas in a study conducted by Khushboo Barjatya et al., only $40 \%$ agreed to this opinion. ${ }^{4}$ Ethnic and racial differences in growth patterns exist at certain ages. This might be the reason for contrasting results.

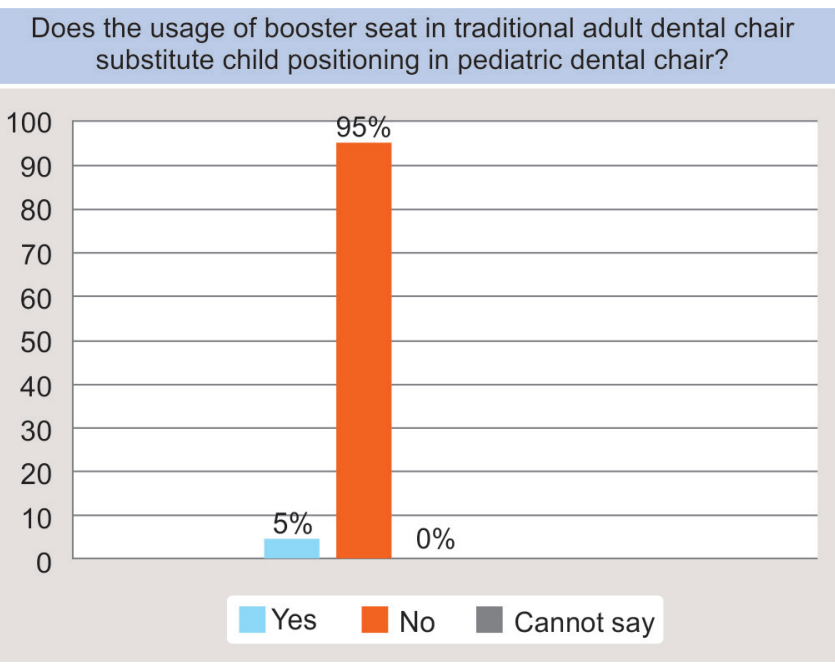

Fig. 5: Opinion about usage of booster seat in adult dental chair

Addition of booster seat to traditional adult dental chair is done to lift the height of child such that operator can gain close proximity to oral cavity of child. Out of $30 \%$ respondents who had experience of working with combination of usage of booster seat in traditional adult chair and pediatric dental chair, $95 \%$ of them said that booster seat cannot substitute child positioning in pediatric dental chair, while only $5 \%$ felt it can be substituted by forward leaning posture of operator.

The attractiveness of pediatric dental chair is more acceptable in children because most of these chairs are in the shape of animals. The use of child-friendly colors in dental workplace and for chairs could enhance a positive dental attitude. ${ }^{5}$ It has been found that the associations of some mood tones with particular colors are more apparent and precise than others. ${ }^{6}$ In the present study, about $97 \%$ of respondents stated that this would instill positive dental attitude in children.

In case of special children and children with Frankel's definitely negative behavior (-), pediatric dental chair is preferable because physical restraints such as Velcro straps can be used safely depending on the situation. This might be the reason for $78 \%$ of participants preferring pediatric dental chair over adult chair in treating special children.

Compactness of pediatric dental chair offers many advantages to both child and pediatric dentist. In our study, $81 \%$ were of the opinion that spittoon is easily approachable to child in pediatric dental chair than adult chair and also $69 \%$ found the instrument tray size to be within reach of arms. Zoidaki et al. stated that positioning of instruments within reach of hands decreases twisting movements while operating. $^{7}$

Four-handed dentistry can be practiced easily in pediatric dental chair because of its narrow backrest and fearful objects such as injections can be easily exchanged. An increase in productivity, ranging from 33 to $75 \%$, has been demonstrated while practicing four-handed dentistry. ${ }^{8}$

When working with pediatric dental chair, $44 \%$ of respondents said that they had no leg space problem, but $36 \%$ felt that they had leg space problem. This might be due to compactness of pediatric dental chair which does not allow them close to operating positioning. To solve this problem, Valachi et al. stated that a base should be positioned more toward the foot of the patient chair as 
it is less likely to become an obstruction by hitting the operator stool pedestal and thus allowing close positioning of the operator. ${ }^{9}$

As this pediatric dental chair offers many advantages to both child and pediatric dentist, $36 \%$ of postgraduates had an opinion that it is not expensive to the benefits it is providing; however, $29 \%$ of them felt that it is too expensive.

Adult chairs are oversized to child; as a result, head may not rest properly in headrest causing inconvenience for child. This problem can be solved with the use of pediatric dental chair; because of its small size, the child will have more comfort in this chair. As the head of child is properly placed in headrest position in pediatric dental chair, light can be effectively focused to the oral cavity which increases the visibility to dentist.

\section{Conclusion}

Acceptance of pediatric dental chair among postgraduates of pediatric dentistry is overwhelming for treating children below 12 years of age. Attractiveness of pediatric dental chair helps in child management. Compactness of pediatric dental chair has many advantages such as headrest adjustment, positioning of child, close proximity of child, spittoon is easily approachable to child, instrument tray size is within their reach of hands of pediatric dentist and four handed dentistry can be easily practiced in pediatric dental chair compared to traditional adult dental chair.

\section{References}

1. Abdolalizadeh M, Jahanimoghadam F. Musculoskeletal disorders in dental practitioners and ergonomic strategies. Anat Sci 2015;12(4):161-166.

2. Newell TM, Kumar S. Prevalence of musculoskeletal disorders among orthodontics in Alberta. Int J Ind Ergon 2004;33(2):99-107. DOI: 10.1016/j.ergon.2003.06.003.

3. Hayes PA. Alternate inexpensive pediatric dental chair. Pediatric Dent 2000;22(3):227-228.

4. Barjatya K, Vatsal A, Kambalimath HV, et al. Pediatric dental chair vs. Traditional dental chair: a pediatric dentist's poll. J Indian Soc Pedod Prev Dent 2015;33(1):35-39. DOI: 10.4103/0970-4388.148973.

5. Umamaheshwari N, Asokan S, Kumaran TS, et al. Child friendly colors in a pediatric dental practice. J Indian Soc Pedod Prev Dent 2013;31(4):225-228. DOI: 10.4103/0970-4388.121817.

6. Wexner LB. The degree to which colors (hues) are associated with mood-tones. J Appl Psychol 1954;38(6):432-436. DOI: 10.1037/ h0062181.

7. Zoidaki A, Riza E, Kastania A, et al. Musculoskeletal disorders among dentists in the Greater Athens area, Greece: risk factors and correlations. Int J Public Health 2013;21(2):163-173.

8. Dalai DR, Bhaskar DJ. Four handed dentistry: an indispensable part for efficient clinical Practice. 2020.

9. Valachi B, Valachi K. Preventing musculoskeletal disorders in clinical dentistry. J Am Dent Assoc 2003;134(12):1604-1612. DOI: 10.14219/ jada.archive.2003.0106. 